\title{
Knowledge Management Process Implementation 2011
}

\author{
Asmahan M. Altaher \\ Applied Science Private University, Jordan
}

\begin{abstract}
The knowledge process is part of organizational life. This paper is focused on the achievements that make Jordan companies ready to implementation KM process. It aims to help in the process of using, sharing, applying the new knowledge. A survey was designed and sent to the all levels of pharmaceutical firms to investigate the factors that effect the KM implementation in order to improve products, services, The result lead recommends that There is a lack of empirical support for the effectiveness and importance of practical knowledge management strategies. The knowledge systems should build with the realization of human knowledge and ideas. Knowledge management requires more attention to IT systems and to the people who sharing knowledge. Firms should use all the options available to motivate employees to put the knowledge in work.
\end{abstract}

\section{Introduction}

Knowledge management may be defined as doing what is needed to get the most out of knowledge resource [1]. What is needed refers to a variety of possible activities involved in KM these activities are broadly intended to discover new knowledge, capture existing knowledge, share knowledge with others, apply knowledge [2]. The implementation of knowledge need to be supported by KM systems and must integration of technologies and mechanisms that are developed to support the above four knowledge management process [3]. Zaim, et al argued that the technology affects the knowledge management process and organization should evaluate the KM system performance [4]. Knowledge management has already been recognized as an important factor of the competitiveness of an enterprise. One of the advantages it brings is speeding up the innovative process by accessing the right knowledge time. It also helps managers to make the right decisions, providing them with all the knowledge actual problems.

Creating knowledge that is very functional and workable for management and decision makers [7]. The purpose of this research was primarily to identify the factors that influence of the effectiveness use of the KM process, in Jordan pharmaceutical industry. The model attempts to incorporate the factors from the literature into a comprehensive array of potential contributors to adoption KM process implementation. This paper investigates the factors that are effects to the implementation of knowledge management process.

In the following section, of the study: Literature reviews Previous Study- Procedurals definition -Research model and hypotheses - Research methodology -result, and conclusion. The knowledge flows had been studied within different industries.

\section{Research Background}

Kevin C. Desouza studied the managing knowledge in healthcare enterprises is hence crucial for optimal achievement of lowered cost of services with higher quality. The paper focuses on developing and fostering a knowledge management process model. The process then viewed through the lenses of various strategies and competitive frameworks [5]. In the other side Charles et al, 2000 argued that knowledge is the most meaningful resource today.

The management of knowledge supports the competitive advantage of organizations. IS mangers perceiving KM to be among the most critical technologies that will drive business growth and innovation. Corporations around the world have identified the need for $\mathrm{KM}$; the paper addressed two needs providing a procedural method for creating a sustainable KM system [6]. In addition Singh ${ }^{\mathrm{A1}}$ and Kant, 2009 introduced understand of similarities and dissimilarities of knowledge management (KM) implementation for different selected sectors of Indian. They were focused on $\mathrm{KM}$ in different functional areas. Furthermore, it indicates that KM practices have their own significance, but the selected sectors adopt them as per their own requirements [8]. Moreover, Picker, Ruhnke, Leker [9] developed a list of factors for knowledge management (KM), using different theoretical frameworks. They identified four elements which were common to most models: management promotion, infrastructure, strategy and evaluation. Conducting four case studies from firms in the chemical industry allowed us to compare our factors with empirical data. They were found that the involvement of top management is crucial for the implementation of KM. KM was seen as a continuous development process. However, one of there interesting findings is that an incentive programmed seems to be necessary for a successful implementation of KM in the culture and processes of an organization [9]. Finally, Braganza [10] outlined two elements, namely, the organization' strategy and its people. Strategic involves refocusing the organization in a direction. She fined that 
people are affected by changes, as they are displaced to other parts of the organization in different roles. She argues that organizations need a process to manage knowledge during periods of radical organizational change. The paper proposes such a process through case study evidence. It highlights actions managers take to ensure that they navigate the paradox of leading the organization through radical change and nurture knowledge. As we mentioned above Km process are importance to the organization. $\mathrm{Km}$ enhanced the extent to which knowledge facilitates the achievement of individual or organization goals.

\section{B-Procedurals definition}

\subsection{Knowledge management Process}

Knowledge is first created in the people's minds. KM practices must first identify ways to encourage and stimulate the ability of employees to develop new knowledge. KM methodologies and technologies must enable effective ways to elicit, represent, organize, re-use, and renew this knowledge [20]. Knowledge support process of discovering, capturing, sharing, applying explicit or tacit knowledge from people, artefacts, or organizational entities [1].

\subsection{Organization strategy}

A set of strategies and facilitations that help employees to surround implicit and explicit restrictions, in order to model the operations, procedures and relationships that help reach their goals [16]. A set of strategies based on a set of insights, experiences and procedures supported by facilitations that guide the thoughts, behaviours and communications of people to reach a goals [20].

\subsection{Individual Expertise}

Expertise can be defined as knowledge higher quality. An "expert" is one who is able to perform a task much better than others. The following are the types of individual experiences

- Associational Expertise

- Motor Skills Expertise

- $\quad$ Theoretical (Deep) Expertise[19]

\subsection{Knowledge Management Technologies}

Technologies that support KM include artificial intelligence (AI) technologies encompassing those used for knowledge acquisition and case-based reasoning systems, electronic discussion groups, computer-based simulations, databases, decision support systems, enterprise resource planning systems, expert systems, management information systems, expertise locator systems, videoconferencing, and information repositories encompassing best practices databases and lessons learned systems [18].

\subsection{KM mechanisms}

KM mechanisms are organizational or structural means used to promote KM .Examples of KM mechanisms include learning by doing, on-the-job training, learning by observation, and face-to-face meetings [18].

\section{Research methodology}

\subsection{Research Model}

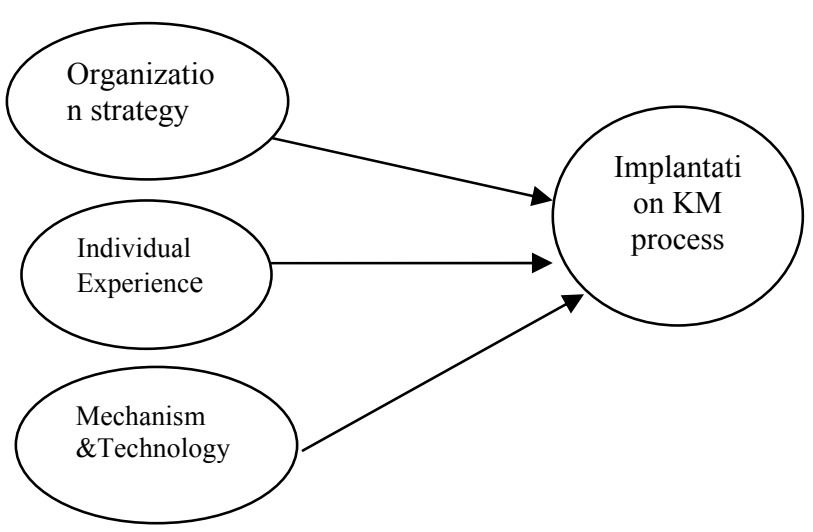

Figure 1. Resources: Adaptive by the researcher

According to Figure 1 the factors that have been defend by [5] [11] [25]. They argued that these factor effects knowledge management process implementation.

\subsection{Hypotheses}

H1 - There is a significant positive effect between the independents factors and the Implantation Knowledge management process

$\mathrm{H} 2$-There is a significant positive effect between organization strategy directions and implantation knowledge management process.

H3- There is a significant positive effect between individual experiences and implantation KM process.

H4- There is a significant positive effect between mechanism and technology and implantation KM process.

\subsection{Quantitative methodology}

Sekaran [11] argues that variables and relationships are the central idea in quantitative research. This is the key objective in this research. Moreover, quantitative methods are very useful in explaining causality requires the establishment of relationships between variable, and linking them to a certain theory. The benefits of quantitative methods provide tools for measuring concepts, 
planning design stages, and for dealing with sampling issues, Therefore, quantitative approach are cost effective, and speed in data collection, the ease of analysis, apposite for testing hypotheses, and determining relationships between variables, and establishing the reliability of data [17].

\subsection{Qualitative methodology}

Qualitative methods focus on generating hypotheses in order to illustrate, and explain the phenomenon in its context, the benefits of the approach become visible by enabling researchers to examine change processes over time, and more in depth and offer rich, and distinctive insights. The criticism of the approach, arising from the fact that it the resource-intensive; analysis, and the interpretation of data is often complex and it requires distinctive skills, lack of well-formulated hypotheses [13].Considering the benefits, and the drawbacks of the two methodologies. In addition to the study limitations, which are discussed below. The researcher adopted the quantitative approach due to the following reasons.

1. Resource Limitation (time, and cost of the study)

2. The issues of validity and, reliability are often seriously questioned because of the nature of the data.

The need to satisfy the research objectives in terms of factor analysis, testing hypotheses, in addition to the verify relationships between the variable, and constructs of the study.

\section{Data collection methods}

\subsection{Collecting data and information resources}

The researcher adopts the qualitative methodology, to satisfy the objective of the study, and the need for a large sample to carry out the data analysis. In addition, the researcher needs to examine the factorial design of the variables of the study, the relationships between the variables, and the advantages and, disadvantages of the questionnaire. In comparison with other data collection methods ,such as face-to-face interviews and telephone interviews .questionnaires are high economy (cost \& time), high efficiency of data collection ,large sample size, wide distribution of sample, while one of the disadvantages is low the response rate [11]. The data, and the information will be gathered from two resources: Primary resources: Individuals focus groups, and a panel of respondents set up by the researcher whose opinions that sought on specific issues from time to time are examples of primary data sources [17]. Data can also be culled from administrating questionnaire. Questionnaires are an efficient data collection mechanism when the researcher knows exactly what is required and how to measure the variable of interest .In the study the questionnaires send to respondents in the senior level, middle managers, top managers and, executive managers. The respondent, profile considered ideal for the study that includes executives as well as top, and middle managers. Secondary resources: Data can also be obtained from secondary sources, as for example company records or archives, industry analysis offered the media Web site, the internet and so on [17]. Using the scientific (Books, articles, etc...) concerned with the study.

\subsection{Questionnaire design}

The questionnaire development process was guided by the following practices:

a) Initial design, is development of the survey instrument.

b) Pre-testing, is enhancement through panel of expert's opinion.

\subsection{Initial design and development of the survey instrument}

Many criteria should be considered when designing a questionnaire survey. On the choice of wording, questionnaire design, and layout were adopted [17].Items in questionnaire were designed to being simple, clear, short, technical, accurate, bias free, and at an appropriate reading level. Recommendations on how to structure the questionnaire layout by [11] [16] were taken into account when designing the questionnaire, such as started with a brief description on how to answer the questionnaire. An initial draft of questionnaire was developed based on an extensive literature review, and existing measures.

\subsection{Data analysis procedure}

The analysis conducted in two stages: instrument validation and hypotheses testing. Statistical techniques mainly are employed in order to examine the hypotheses.

\subsection{Sample size determination}

Based on the work of the determination of sample size took into account the following:

- What is the acceptable margin of error in the formula? Firstly, the independents variables are organization strategic, individual experiences, technology and mechanism. The dependent is KM process implementation. The researcher use Likert scale [1].

\subsection{Decisions related to population and sample selections}

The pharmaceutical industry is an appropriate business environment that is particularly suitable to test for the research model and the determinations of the factors that 
effect KM process implementation, in Jordan. Fourteenth companies, five companies controlling the local market and, account for more than $90 \%$ of the country's total production, another objective in choosing pharmaceutical companies was to maintain the extent of manageable study. Sekaran [11] defined research population as any exactly defined set of people, or collection of items, that is under investigation. In the light of this definition, the research population, and the actual sample are identified as that the four companies dominate the local market and account for more than $90 \%$ of the country's total production. These are Hilkma, DAD, JPM, and mid Pharmacy. Questionnaires was send to respondents managers worked in (Research \& Development and marketing Departments) currently working in the companies. A stratified random sampling method used, as it is the most convenient, and the most applicable in the Jordan context. 300 Quaternaries were sent to 300 populations of companies 232were returned, 17 Questionnaires were ignored because it has missed. The overall response rate for this study is $77 \%$. However, it is found that sample is sufficient to represent the regression analysis conducted.

\subsection{Operationalisation and measurement strategy of the model variables}

The measures of model variables in this were operatinalise using statistical procedures starting with internal consistency test, establishing constructs reliability, statistical procedures are common among many researchers, such as [13] [16].

1- Internal consistency to assess the reliability of the scale using Combach's alpha.

2-Investigating hypothesizes by Pearson correlation, and mean and standard deviations.

\subsection{Descriptive statistics}

Descriptive statistics such as means frequencies was use to identify the major characteristics of respondents in term of their gender, age, education level, working experience and, working position.

Table 1. Descriptive statistics

\begin{tabular}{|l|l|c|}
\hline \multirow{2}{*}{ Demographic object } & The valid items & Percent \% \\
\hline \multirow{2}{*}{ gender } & Male & 65.7 \\
\cline { 2 - 3 } & Female & 34.3 \\
\hline \multirow{2}{*}{ Education level } & College degree & 9.5 \\
\cline { 2 - 3 } & Bachelor degree & 83.4 \\
\cline { 2 - 3 } & Postgraduate degree & 7.1 \\
\hline Working experience & Less than 6 & 9.0 \\
\cline { 2 - 3 } & From 1-2years & 36.0 \\
\cline { 2 - 3 } & 5-10years & 30.33 \\
\hline
\end{tabular}

\begin{tabular}{|l|l|c|}
\hline & More than 10 & 24.67 \\
\hline \multirow{3}{*}{ Managerial level } & Administrative staff & 12.8 \\
\cline { 2 - 3 } & Technical staff line & 36.5 \\
\cline { 2 - 3 } & Manger senior/leader & 27.0 \\
\hline
\end{tabular}

\subsection{Internal reliability}

The internal consistency measures (Cronbach,s Alpha) are obtained in order to assess the reliability of the measurement instruments. The Table 2 shows the Cronbach,s Alpha value for each scale. It is clear that Cranach alpha is valid, acceptable statistically and managerially because $(\alpha)$ values are greater than accepted percent 0.60 .

Table 2. Descriptive statistics

\begin{tabular}{|l|l|c|}
\hline No. & Variables & $\begin{array}{c}\text { Cronbach's } \\
\text { alpha( }(\boldsymbol{\alpha})\end{array}$ \\
\hline 1 & $\begin{array}{l}\text { Implantation Knowledge } \\
\text { management process }\end{array}$ & 0.833 \\
\hline 2 & Organization Strategic & 0.823 \\
\hline 3 & Individual experiences & 0.704 \\
\hline 4 & Technology and mechanism & 0.782 \\
\hline
\end{tabular}

\section{Result}

Measuring the effect between the independent variable and dependent variable simple regression

Most of the respondents agree that they have good and close relationship with Mean=3,78; $\mathrm{SD}=0.54$ ). Te result of the regression analysis shows that there is a significant positive relationship between the independent variables and $\mathrm{KM}$ process implementation $(\mathrm{p}<0.001)$. With $43.4 \%$ of variance in level of $\mathrm{Km}$, process implementation explained by the relationship of the sum of organization strategy, individual experiences, technology and mechanism. The hypothesis 1 is supported.

\section{The effect between strategic directions and} implantation $\mathrm{Km}$ process

Table 3. The effect between strategic directions and implantation KM process

\begin{tabular}{|l|l|l|}
\hline Variables & Pearson correlation & Sig \\
\hline $\begin{array}{l}\text { Organization and } \\
\text { strategy } \\
\text { knowledge } \\
\text { management process }\end{array}$ & & 0.000 \\
\hline
\end{tabular}

on the results in Table 3 which relate to correlation between the independent variable (organization strategic) and the dependent variable (knowledge management process), we can find a positive, and significant effect at function level $(\alpha \leq 0.01)$ which supports hypothesis (Ha1- 
$1)$, where $(\mathrm{r}=.467)$. Based on the results in table (3) which represent simple regression analysis, Simple regression was used to test above hypothesis, and it was found that calculated $t(7.642)$ is significant at $(\mathrm{p}<0.001)$ level, which means that there is a relationship between organization strategy and KM process implementation variance equal $48 \%$. We can see significant effect at function level ( $\alpha \leq$ 0.01 ) to the independent variable (strategic directions) in the dependent variable (knowledge management process). The hypothesis 2 is supported.

\section{The effect between individual experiences and implantation KM process.}

Table 4. The effect between and individual experiences, implantation KM process

\begin{tabular}{|l|c|c|}
\hline \multicolumn{1}{|c|}{ Variables } & Pearson correlation & Sig \\
\hline $\begin{array}{l}\text { Individual } \\
\text { experiences and } \\
\text { knowledge } \\
\text { management process }\end{array}$ & .492 & 0.000 \\
\hline
\end{tabular}

Based on the results in table (4) which relate to correlation relationship between the independent variable Individual experiences and the dependent variable knowledge management process, we can find a positive and significant effect at function level $(\alpha \leq 0,01)$ which supports hypothesis $\left(\mathrm{H}_{\mathrm{a} 2}\right)$. Based on the results in table (4), which represent simple regression analysis, Simple regression was used to test above hypothesis, and it was found that calculated $\mathrm{t}(10.609)$ is significant at $(0.01)$ level, which means that there is a relationship. We can see significant effect at function level $(\alpha \leq 0.01)$ to the independent variable in the dependent variable (knowledge management process). The variance is (0.428). The hypothesis 3 is supported.

\section{The effect between technology, mechanism and implantation knowledge management process}

Table 5. The effect between technology, Mechanism and implantation KM process

\begin{tabular}{|l|c|c|}
\hline \multicolumn{1}{|c|}{ Variables } & Pearson correlation & Sig \\
\hline $\begin{array}{l}\text { Technology, } \\
\text { mechanism and } \\
\text { knowledge } \\
\text { management process }\end{array}$ & .468 & 0.000 \\
\hline
\end{tabular}

Based on the results in table (5) which relate to correlation relationship between the independent variable (technology mechanism ), and the dependent variable (knowledge management process), we can find a positive and significant effect at function level $(\alpha \leq 0.01)$, which supports hypothesis (Ha3 )Table (5) Simple regression was used to test above hypothesis and, it was found that calculated t (10.325), is significant at (0.01) level, we can see significant effect at function level $(\alpha \leq 0.01)$ to the independent variable in the dependent variable (knowledge management process). The variance is (0.29). The hypothesis 3 is supported. The hypothesis 4 is partially supported.

The study contributes to expanding body of research on the field of the factors effects, KM process implementation. The study shows that there are three factors affect the KM process; the first one is organization strategy the result shows that Jordan pharmaceutical companies concerned with their strategy, they are committed to marketing objects, and services process mission, The firms give attention to capture, document, and analysis there knowledge . From the mean and standard deviation there is a lack of empirical support for the effectiveness and importance of practical knowledge management strategies, we can justify that because of the organization strategy isolate of KM strategy. This is agreeable with Brockmann [11] he believes that companies developing deep knowledge by understanding the objectives and strategy of there firms and, make there strategy deepens in that knowledge; this is an essential part of creating new knowledge. The results lead to recommend that companies should focus in their organization strategy and linked between the strategy and KM process. The second factor was the individual experiences, from the mean we can see that the individual turnovers are in high level. When an organisation intends to increase its knowledge management practice, it must initially use its own specialists, and that not available in Jordan firms. More important than any factors, the firms need to support and empower the individual to keep them in work long term, which will make the individual accumulate new knowledge and experiences [12]. Pharmaceutical firm in Jordan need to enrol the employees in training. The researcher recommends that firms should use all the options available to motivated employees to put knowledge to work. However, individuals are important factor to support sharing, and applying knowledge management process [14]. While for technology and mechanise in pharmaceutical companies, there is participation in data links, and most of the companies encourage employee to interact in regular basis through electronic channels. Further, the study shows that pharmaceutical companies in Jordan use different technology tools to support knowledge management process such as groupware, brainstorming, and dolphin methods. The storage and access of technical knowledge is always a concern. Market intelligence, competitors' information, and customers' feedback are easily stored and accessed [15]. Organisation is knowledge rich but the access to a categorisation is less robust. Considerable effort and resources are needed to capture and keep it current. 


\section{Conclusion}

The study highlights some issues that attempts to make knowledge available through discovering, capturing, sharing and applying knowledge. KM focuses on organizing and making available important knowledge, wherever and whenever it is needed. The researcher argued that there is a lack of support for $\mathrm{km}$ process and the practical knowledge management strategies still need more work. Managers sink billions of dollars into technology rather than focusing on developing their own integrated strategies to manage their organisational individual. In the other hand the employee turnover rates is in high level in pharmaceutical firms. Employee turnover in high rates have resulted in individuals with decision-making authority having less tenure within their firms. The researcher recommends that firms should use all the options available to motivate employees to put the knowledge in work.

Finally the technology facilitates knowledge sharing as well as accelerated growth in the new knowledge. The use of leading-edge technologies to support KM mechanisms enables dramatic improvement in KM. In my view the knowledge management requires more attention to IT systems and people who sharing knowledge.

\section{Acknowledgement}

The author is grateful to the applied science private university, Amman, Jordan, for the financial support granted to cover the publication fee of this research article.

\section{References}

[1] Fernandez, I. B. Conzalez., A. Sabherwal, R., (2004). Knowledge management challenges, solutions, and technologies: Pearson Education, Inc., New jersey, United states of America.

[2] Davenport and Prusak, (2000), Working with knowledge: how organization managing what they know", Harvard business school press, Boston. www.print.com, (Access date: 29.5.2010).

[3] Wilkesmann, U., Wilkesmann, M., Virgillito, A., (2007). Requirements for knowledge transfer in hospitals: How can knowledge transfer be supported in hospitals?, Discussion papers des Zentrums für Weiterbildung Universität Dortmund, ISSN 1863-0294.

[4] Zack, M. H., (2001), " Developing a knowledge strategy: epilogue". Available at: http:// web .cba.neu.edu/- mzack /articles. (Access date: 22 Dec 2010.

[5] Desouza, K. C., (2002) Knowledge management in hospitals: a process oriented view and staged look at managerial issues, Volume 4, Number 6 / 2002. p.478 - 497.

[6] Snyder, C. A., Johnson McManus, D., Todd Wilson, L., (2000) corporate memory management: a knowledge management process model, International Journal of Technology Management, Volume 20, Numbers 5-8 .P. 752 - 764.

[7] El-Korany, (2007) A knowledge management application in enterprises. International Journal of Management and Enterprise Development, Volume 4, Number 6, P.693 -702.

[8]Singh A1M.D R. Kant A2 (2009) knowledge management implementation issues: a sectorial analysis, International Journal of Innovation and Learning, Volume 6, Number 5 / 2009 P 493 516.

[9] Picker, A. R., Leker, J., (2009) Knowledge managementwhat makes the success, International Journal of Technology Management, Volume 45, Number 3-4 / 2009 P 380 - 389.

[10] Braganza., A., (2002), Knowledge management during radical change: applying a process oriented approach, International Journal of Entrepreneurship and Innovation Management, Volume 2, Numbers 4-5 / 2002. P294 - 307.

[11]Sekaran, U., (1992). Research Methods for Business: A skill Building Approach, Second Editions, alynow university press, USA p (285-301).

[12] Brockmann., E. N., (2008), Using more of your existing knowledge to make better strategic decisions, International Journal of Learning and Change, Volume 3, Number 2 /P. 145 162.

[13] Koumpouros, Y., Nicolosi, G. L., Martinez-Selles, M., (2006), Critical success factors for establishing a multidisciplinary health community knowledge management system using internet-based ICTs: the cardiology paradigm, International Journal of Healthcare Technology and Management, Volume 7, Number 3-4, P. 283 - 302.

[14] Biloslavo, R., (2005), Use of the knowledge management framework as a tool for innovation capability audit, International Journal of Innovation and Learning, Volume 2, Number 4, P 402 $-424$.

[16] Hawari, M., (2004), Knowledge Management Styles and Performance: a Knowledge Space Model from both Theoretical and Empirical Perspective, thesis submitted in the university of Wollongong.

[17] Firas, A., (2003), An integration of information technology, culture of knowledge transfer and innovative work environment in support of organization al knowledge creation activities, unpublished Ph.D thesis, University of Huddersfield.

[18]Davenport and Prusak, (2000), Working with knowledge: how organization managing what they know", Harvard business school press, Boston. www.print.com, (Access date: 29.5.2010).

[19]Yu, H., Tatoglu, E., Zaim, S., (2007), Do we know what really drive KM performance Journal of knowledge management 11(6): 39-76.

[20] Zack, M.H., (2001), " Developing a knowledge strategy: epilogue". Available at: http:// web .cba.neu.edu/- mzack /articles. (Access date: 9 November 2010). 
International Journal of Digital Society (IJDS), Volume 1, Issue 4, December 2010 